\title{
Torture Pornopticon: (In)security Cameras, Self-Governance and Autonomy
}

\section{Steve Jones}

"Torture porn" films are characterized by shared narrative themes: abduction, imprisonment and suffering. ${ }^{1}$ In this subgenre, individual hostages provide narrative focus and dominate the screen-time. The subgenre's prevalent visual tropes confirm that attention is squarely fixated on torture porn's abductees rather than its abductors. This chapter examines one such set of motifs. More than 45 torture porn films feature CCTV (including Captivity (Roland Joffe, 2007), Invitation Only (Kevin Ko, 2009), and Torture Room (Eric Forsberg, 2007)). Photographic cameras, photographs, camcorders, super-8 cinecameras, and footage made to appear as if shot via those cameras feature just as heavily (see, for instance, Frontier(s) (Xavier Gens, 2007), I Spit on Your Grave (Steven R. Monroe, 2010), Penance (Jake Kennedy, 2009) and Wolf Creek (Greg Mclean, 2005)). As the onscreen presence of cameras underlines, prisoners are constantly overseen by their jailors. In these films, closed-circuit cameras signify the looming threat posed by antagonists. Resultantly, the presence of cameras amplifies the protagonists' fear and paranoia. Security cameras signify a bridging point between the jailors' ability to observe and propensity to control their prey. Power is skewed in the all-seeing abductors' favour since they can monitor and counter any attempts to resist their oppressive rule.

In these regards, torture porn's prison-spaces are panoptical. Despite failing to encapsulate contemporary surveillance's complexities, ${ }^{2}$ the panopticon paradigm remains influential within surveillance studies because it captures essential truths about the psychologies of self-governance and intersubjectivity. ${ }^{3}$ Following Foucault's influential appraisal, ${ }^{4}$ the panopticon is synonymous with power-relations that are underpinned by sinister intent and the anxiety disempowerment causes. Accordingly, the panopticon lends itself to understanding how surveillance operates in horror fiction's fear-fuelled contexts. The panopticon elucidates how and why terror is augmented by the presence of "all seeing" cameras within torture porn's diegetic prisons. This chapter will use torture porn's panoptical spaces and captor-captive relationships as a springboard into examining how self-preservation, self-governance, and self-centredness manifest in torture porn. The CCTV motif illuminates the relationship between two conflicting impulses: interdependence and independence. The former is inherent to socially situated selfhood, and is epitomised by the compulsion to preserve social cohesion even when the result impinges on the agent's individual inclinations and prospects. Independence, in contrast, is epitomised by the will to autonomy and the desire to entirely govern oneself. Since interdependence compels one to act primarily for and with others (rather than for oneself), the ideals of autonomy and interdependence are divergent. Consequently, intersubjective beings are torn between these two sets of conflicting impulses. In torture porn's panoptical settings, such innerstruggles are exposed in an exaggerated fashion. 
Linnie Blake and Xavier Aldana Reyes (eds.) Digital Horror: Haunted Technologies, Network Panic and the Found Footage Phenomenon. London: I.B. Tauris, 2016, pp.29-41

This version (C) Steve jones, 2015

This chapter begins by outlining what the panopticon is and how it manifests in torture porn. The chapter's second section will focus on self-governance and fear, delineating complications that arise within the panopticon paradigm. The concluding section will develop that commentary by reflecting on broader concerns evoked by torture porn's rendition of surveillance: namely, that constant supervision may stimulate self-invested paranoia, and so could have a deleterious effect on social bonds. Beyond the realm of fiction films, digital surveillance operates on such an enormous scale that it appears to be elusive and indefatigable. The extent to which digital surveillance impacts on individuals' lives and behaviours remains unclear to the vast majority of the populace, and this is one reason that surveillance evokes trepidation. Contemporary horror reifies this nebulous fear, offering microcosms in which individual fear and concrete harm are actualized. Thus, torture porn's rendition of surveillance offers insights into how power operates in contemporary digital horror more broadly; such anxieties abound in horror texts set against the context of "fear culture."

\section{"Someone is watching:" ${ }^{5}$ The Panopticon}

The panopticon is a form of penal architecture designed to make prisoners permanently visible to guard staff. Foucault's influential essay on the panopticon highlights the powerful dynamic that underpins Bentham's design. For Foucault, the inmate's "permanent visibility assures the automatic functioning of power." ${ }^{\prime 6}$ The threat of being viewed is a potent deterrent to wrongdoing: the inmate understands that they are likely to be caught if they engage in prohibited activity. Concurrently, the guard-station is hidden behind meshwork in Bentham's design, meaning detainees cannot tell when they are being watched, or by whom.

Despite temporal and technological distance from the seventeenth-century leper colonies Foucault refers to, his description of "strict spatial partitioning" whereby individuals are "placed under the authority of a syndic" and "forbidden to leave on pain of death" is uncannily echoed in torture porn's "locked box" environments. The bathroom in which Adam (Leigh Whannell) and Lawrence (Cary Elwes) are imprisoned in Saw (James Wan, 2004 ) is an archetypal example: the hostages are detained in a single room that is surveyed by CCTV, and they are punished (electrocuted) when they deviate from stipulated "rules." This ethos is augmented in various subsequent torture porn films. In Coffin (Kipp Tribble and Derik Wingo, 2011) and Meadowoods (Scott Phillips, 2010), captives are studied via closedcircuit cameras fitted within burial-caskets. In these intensified "locked box" circumstances, protagonists are unable to hide even the smallest indiscretions. In House with 100 Eyes (Jay Lee and Jim Roof, 2011) the "locked box" space is larger (an entire residence), but the quantity of cameras is amplified: the locale is a "soundproof, escape-proof...cage," which is monitored from "all angles."

Indeed, numerous torture porn films use surveillance motifs to confirm that the antagonists could be anywhere and can see everything. For example, Vacancy 2: The Final Cut (Eric Bross, 2008) centres on motel owners who make snuff films in which the guests "star" as 
Linnie Blake and Xavier Aldana Reyes (eds.) Digital Horror: Haunted Technologies, Network Panic and the Found Footage Phenomenon. London: I.B. Tauris, 2016, pp.29-41

This version (C) Steve jones, 2015

victims. The stalking sequences are interpolated by numerous shots recorded via CCTV cameras and the murderers' camcorder. These shots are marked by shifts in aesthetic: green-filtered shots and lightly distorted, treble-heavy audio are used to denote the switch to camcorder footage, for instance. Yet that literal surveillance infects the film's aesthetic approach more generally. Even when no camcorders or CCTV cameras are present in the diegetic space, the film-camera adopts the free-roaming handheld shots and unsteady crash zooms that characterize the killers' unprofessional camcorder footage. Emulating their viewpoint in this way implies that the killers' sovereignty is totalising, since it pervades Vacancy 2's form.

Surveillance is rarely covert in torture porn: hostage-takers actively foster the impression that they see all. Early in Breathing Room, a jailor disguised as an abductee feigns electrocution after he breaks one of the arbitrary rules imposed upon the captives (crossing a line on the ground). Unaware of the deceit, the prisoners believe they are under unerring surveillance and modify their behaviour accordingly. Thus, when attempting to remove their "electrified" neck-collars, they cower in one corner of the cell waiting for the CCTV camera to momentarily pan away. In these moments, over half the frame is dominated by the rotating surveillance camera, underscoring its symbolic supremacy. The detainees' adaptation to circumstance is indicative of how the panopticon operates. Once established in concept, the hostages maintain the power-skew that disadvantages them: their modified behaviour confers power onto the jailor. As Jackson, Gharavi and Klobas observe, the panoptical arrangement is designed to ensure that "surveillance is permanent in its effects, even if it is discontinuous in its action." ${ }^{8}$

Ergo, it matters little if the abductor is able to see all. In Death Factory: Bloodletting (Sean Tretta, 2008), lead captor Denny (Noah Todd) proclaims that "there are cameras everywhere, we see everything." Despite being known as "Big Brother," Denny's claim is exaggerated: audio is not monitored and one camera ceases to function. Ignorant of such failures, captives such as RubberLover (David C. Hayes) corroborate Denny's supremacy by affirming that they are trapped by "men who like control." His assessment is immediately followed by a shot of Denny watching the CCTV displays, which underscores the connection between RubberLover's estimation and Denny's authority. Being seen to be omnipresent conveys that resistance is impossible. Cameras manifest the hostage-taker's apparent omnipresence and confirm their ostensible omniscience. Yet, the abductees cannot verify when or even if they are being watched. The knowledge-bias confers power onto the jailor. Since the jailor already has physical rule over the prisoner - having captured them - the abductor's apparent omniscience-qua-sovereignty is translated into potential omnipotence.

Because they internalize their captors' presumed and unerring judgement, hostages are "caught up in a power situation of which they themselves are the bearers." ${ }^{19}$ The panopticon functions in lieu of the oppressors' continuous, explicit presence because captives autoregulate their behaviours. This principle is evident in 99 Pieces (Anthony Falcon, 2007), for instance. After his wife is abducted by an unknown assailant, Joshua (Anthony Falcon) is told he must complete a puzzle in order to save her. At the hostage-taker's bidding and out of fear of potential ramifications, Joshua turns his own home into a prison, boarding up his doors and windows. The jailor assures Joshua that his every move is being examined and 
Linnie Blake and Xavier Aldana Reyes (eds.) Digital Horror: Haunted Technologies, Network Panic and the Found Footage Phenomenon. London: I.B. Tauris, 2016, pp.29-41

This version (C) Steve jones, 2015

failure to obey his rules will result in a loss of "points:" an arbitrary currency Joshua must use to purchase survival-essentials (food, water or electricity). Joshua adheres to the system, self-regulating by deciding how to spend his points-currency. This regime of internalized management illustrates the pernicious power-relations the panopticon instils.

Joshua's submission illustrates that once established in the concrete of one's immediate environment, power-biases are compelling. As Foucault has it, once the power-dynamic has been established, it requires minimal enforcing because visibility itself "is a trap." ${ }^{10}$ Even in torture porn's explicitly trap-like environs, minimal enforcement is required to maintain authority. For example, Hunger's (Steven Hentges, 2009) nameless jailor has no direct contact with the abductees. The prisoners have no means of comprehending who is tormenting them or why. The hostages compensate by internalising their abductor's authority, anticipating his desires. After receiving a carving knife and a note stating that "the average human body cannot last for more than thirty days without food," they secondguess what the captor requires of them. Lead protagonist Jordan (Lori Heuring) assumes that "he wants" them to eat each other: "you know that's why he has us down here." Luke's (Joe Egender) response - "what other choice do we have?" - conveys his adherence to that presumed desire, even though no direct command has been stipulated. Once imprisoned, the hostage-taker does little to coerce the hostages: they become co-authors of their own oppression.

\section{"You may not see any threat, but there are threats all around you:"11 Fear and Self- Governance}

Irrespective of how clear-cut torture porn's panoptical power-dynamics are (at least initially), the implications that follow are murkier. Two paradoxes stem from panoptical dominion as it is established in torture porn. The first relates to the level of attention paid to the abductees. Imprisoned protagonists are inspected in detail via the jailor's surveillance set-up. In many cases, torture is also designed specifically for each abductee. For example, the prisoners in Are You Scared? (Andy Hurst, 2006) are subjected to their "innermost fears," meaning that elaborate torture devices are manufactured exclusively for each detainee. So, Brandon (Brad Ashten), who is achluophobic (afraid of the dark), is forced to traverse a pitch-black room rigged with trip-wires that will trigger numerous assault rifles. In such cases, the jailor's exaggerated interest in the hostages is perversely flattering: prisoners are connoted to be worthy of the abductor's maniacal scrutiny, which is reified by the CCTV cameras. The abductor's transfixion on individual abductees might seem like the stuff of egoistic fantasy - of adoration and worship - were it not for the fact that victims are destroyed by their captor's fascination. Such threatening yet devoted focus is evoked in Saw when John (Tobin Bell) asks Paul (Mike Butters) whether his suicide attempt was genuine, or whether he just wanted "some attention." The attention Paul consequently receives entails his entrapment in John's lethal barbed-wire snare.

In torture porn's panoptical spaces, imprisonment simultaneously bolsters and damages the detainee. These forms of emphasis imply that hostages stimulate their own victimisation. 
Linnie Blake and Xavier Aldana Reyes (eds.) Digital Horror: Haunted Technologies, Network Panic and the Found Footage Phenomenon. London: I.B. Tauris, 2016, pp.29-41

This version (C) Steve jones, 2015

Although they face death, then, the captives' survival is also required to sustain the hostagetaker's agenda. Moreover, abductees are required to damage themselves on the jailor's behalf. The second paradox arises out of that conflict. The panopticon model requires the prisoner to entirely submit to their jailor's ostensible omnipotence, relinquishing autonomous control. Simultaneously, the panopticon foists maintenance of that subordination onto the detainee, who is required to self-govern. In many instances, torture porn's abductees are unable to fulfil the tasks set for them; ${ }^{12}$ where this is the case, the captive's powerlessness affirms the captor's absolute control.

Hostages are not only coerced into self-oppression, but are also expected to internalize culpability for their suffering, regardless of the degree to which they can shape their circumstances. In Senseless (Simon Hynd, 2008), Eliott (Jason Behr) is captured and tortured because his lifestyle epitomizes affluence, freedom and indulgence. As his abductor Blackbeard (Joe Ferrara) has it, they make "an example of" Eliott, broadcasting the torture Eliott undergoes. Blackbeard refers to Eliott's "punishment" as a process of "collaboration," asking Eliott to "work a little more closely with" his captors; "practice your screaming, please" (emphasis in original). Despite frequently trying to fight against his hostage-takers, flashbacks reveal that Eliott comprehends his imprisonment as karmic punishment for events unconnected to his torture. For example, Eliott recollects that as a boy, he stole money from a blind youth. The gap between Eliott's personal guilt and the torture he undergoes is bridged in Senseless. Just before he is deafened, Eliott recalls confessing his offence against the blind boy to the local community. Blackbeard's subsequent pronouncement - "never forget what you have done ... you are not innocent" - appears to refer to Eliott's minor childhood infringement because the flashback is interjected during the torture-sequence. Eliott uses his unrelated wrongdoing to comprehend the "senseless" punishment he is subjected to. In this regard, Eliott does indeed become a "collaborator" in his own punishment.

In the subgenre's scenarios then, it is not entirely clear who has greater control over the captive: the jailor or the abductee themselves. In Hunger, that conflict is explicitly articulated by one prisoner, Anna (Lea Kohl): "I decide who lives or dies, so who's controlling who[m]?" The paradoxes are unsettling, not least since fear is underscored and simplistic resolutions are debunked in torture porn films. Although torture motivates the subgenre's characters insofar as threat creates urgent circumstances and requires immediate action, the subgenre's protagonists are also impelled by two competing practices: obedience (bowing to or internalizing another's will) and independent, autonomous self-governance.

Although we perceive ourselves as autonomous individuals, we are prone to complying with forces that persuade us to act in ways that we otherwise would not independently choose to. When asserted with enough power, seemingly independent beings can be convinced to behave in ways that augment their own disempowerment. By regularly engaging with this theme, torture porn dramatizes a set of ideas akin to Lusztig's concern that self-governing citizens "are vulnerable to the despotic impulses" of authority figures, and "are susceptible ... to socially akratic preferences." ${ }^{\prime 13}$ Indeed, torture porn's protagonists frequently relinquish "higher" moral values in favour of immediately pressing short-term goals: survival and escape. Doing so routinely entails abductees turning on one another, sacrificing fellow 
Linnie Blake and Xavier Aldana Reyes (eds.) Digital Horror: Haunted Technologies, Network Panic and the Found Footage Phenomenon. London: I.B. Tauris, 2016, pp.29-41

This version (C) Steve jones, 2015

captives in order to preserve their own safety. In torture porn's threat-laden panoptical contexts, the ability to self-govern commonly manifests via the will to self-preserve. Where captives are forced to choose whether to save themselves or their fellow captives, interdependency typically buckles to self-invested paranoia in these narratives.

Detainees are often strangers to one another, and frequently cannot apprehend why they have been abducted. Faced with such uncertainty, it is unsurprising that captives should be impelled by what they can apprehend: the pressing (presumed) danger they face. For example, despite being told that their objective is to "heighten [their] loyalty and cooperativeness," the abductees in Deathtube (Yohei Fukuda, 2010) prioritize their own survival. As one protagonist observes, "competition inevitably makes winners and losers:" had they all refused to compete in the life-and-death games laid before them, they would all have survived. Such an agreement would require collective solidarity and mutual trust. As soon as one prisoner breaks rank, the group-bond dissolves. Indeed, as Deathtube progresses, the detainees increasingly seek to ensure their survival by deceiving and outright attacking one another. Deathtube's surveillance-based "broadcast murder show" relies on and relishes in their back-stabbing.

Deathtube's closed community of self-effacing strangers echoes the visions of fracture found in recent scholarship regarding surveillance and autonomy, including Oliver's description of a "paranoid culture where power is both everywhere and nowhere oppressing us," which leads individuals to "exclude others,"14 and Elmer and Opel's account of "inevitable...invisible" attack waged on a "survivor society," in which "each individual's responsibility" is to "ignor[e] their 'erroneous' instinct to help others." 15 One Deathtube hostage is the mouthpiece for this mind-set, flatly declaring, "I want to survive, I don't care about others."

The logical conclusion of that impetus is even more disquieting. Many captives do not just subjugate themselves or fail to help others: they also harm fellow abductees on their jailors' behalf. The abductor in Panic Button (Chris Crow, 2011) makes no direct physical contact with the prisoners and even his verbal exchanges are mediated via a computer-animated alligator. The captor's supremacy is expressed via seemingly boundless knowledge about the detainees' personal lives, gleaned by data-mining "readouts of every website [they] have visited." This bank of prior surveillance-based knowledge is inextricable from visual scrutiny the hostages face in the narrative present. For example, lead protagonist Jo (Scarlett Alice Johnson) pleads with fellow captives to follow the hostage-taker's instructions because "[he] can see us." The abductees relinquish to the jailor's authority, asserting that "he's in control here, there's nothing we can do." The protagonists are not simply passive self-subjugators, however. The prisoners confirm the jailor's sovereignty by undertaking some agency in their oppression. When the abductor threatens to kill individuals from each detainee's social networking "friends" list, the hostages agree to attack one another. The move demands that the captives choose between their established "real-world" community bonds, and their immediate grouping (the community of abductees). By framing these as mutually exclusive, the captor ensures that the prisoners do not pool their collective might to facilitate their escape. Although they seek to defend their ties to existent communities, conspiring with their hostage-taker is a self-effacing gesture. 
Linnie Blake and Xavier Aldana Reyes (eds.) Digital Horror: Haunted Technologies, Network Panic and the Found Footage Phenomenon. London: I.B. Tauris, 2016, pp.29-41

This version (C) Steve jones, 2015

The compliant detainees fail to apprehend why communities are worth defending. Abduction enervates the hostage by extracting them from their communal support systems, in which power is (relatively) evenly distributed. Creating an environment in which distrust is rife further enfeebles the isolated captives. By distancing themselves from the other abductees, the prisoners focus power onto the jailor and away from the trapped group.

The surveillance apparatus signals that the jailor has the capacity to focus on the hostage's movements in minute detail. The abductor's attention is physically manifested via CCTV cameras, the obviousness and tangibility of which distract from what is not subject to scrutiny within the panoptical setting. If the captives studied themselves in as much detail as the captor does, the protagonists would attain greater control over their situation. The abductees do not simply suffer because they are oppressed, but because they forsake selfcontrol by opting to engage in violent, contra-social behaviours out of fear. Torture porn's principal source of horror stems from instances of torture. Even so, torture is facilitated by group-fracture and the self-invested paranoia that a panoptical dynamic inculcates.

\section{"We're on our own:"16 Fear and Communal Decline}

For Foucault, the panopticon was a metaphor for how society is shaped by disciplinary structures. In torture porn, panoptical prison-spaces also underscore the relationships between the individual, power, and community. These films typically represent selfcastigation as inseparable from the punishment of others. Indeed, the subgenre's surveillance motifs code even the most private, surreptitious, individualized wrongdoing as having a "public" dimension. Torture may occur in closed-off spaces in Are You Scared?, Panic Button, Senseless, Untraceable (Gregory Hoblit, 2008), and Deathtube, but the surveillance footage is also broadcasted. In the latter three films, the public interact with and spur on the prisoners' torture. Pace Taskale's vision of "the new terror," which is "highly invisible, off-scene,"17 torture porn frequently reifies detainees' anguish as public spectacle: the "new terror" is decidedly visible. Although the subgenre's exhibitions of agony signal an increased public interest in spectacle, the torture is imbued with a regulatory character. Cruelty is certainly displayed, yet the subgenre is concerned with unpicking the effects discipline has on the diegetic populace.

In torture porn, forcible castigation is less impactful than coercive terror. The latter is augmented by the panoptical regime, which obfuscates sources of hazard. Torture porn's self-empowered, anti-communal, all-pervasive hostage-takers are veiled not only by their irrational, even incomprehensible motives, but also by their anonymity. From the hostage's perspective, the jailor is unknowable because he or she is represented by the cold, erring gaze of CCTV cameras. This apparatus reveals nothing of the jailor's location or objectives. Moreover, the captives commonly face unexpected danger from within the prison-space, because fellow abductees are coerced into enacting violence on the abductor's behalf. This trait is magnified in films such as Saw II (Darren Lynn Bousman, 2005), The $7^{\text {th }}$ Hunt (Jon Cohen, 2009), and Captivity where torturers present themselves as fellow prisoners. Such deception fosters paranoia. Being unable to apprehend where threats might arise from, 
Linnie Blake and Xavier Aldana Reyes (eds.) Digital Horror: Haunted Technologies, Network Panic and the Found Footage Phenomenon. London: I.B. Tauris, 2016, pp.29-41

This version (C) Steve jones, 2015

everything becomes a potential stimulus for anxiety for the detainees trapped in torture porn's panoptical spaces.

In this regard, torture porn feeds from the notion that we are currently living in a "culture of fear:"18 a shared milieu of terror that has no single, identifiable cause. Notwithstanding the impetus to curb or at least discourage immoral behaviours via widespread CCTV, surveillance intensifies the kind of anxiety "fear culture" refers to; as Fox contends, "[r]outine surveillance creates an abiding sense of communal unease." ${ }^{19}$ There are four reasons why surveillance inspires such trepidation. First, surveillance is indiscriminate. The security camera captures footage of anyone who falls before its lens. Greater coverage (more cameras) increases one's chance of exposure. Surveillance treats all persons as equals, albeit in the punitive sense: the entire populace is placed under suspicion. Second, constant supervision encourages self-consciousness rather than social awareness. There is no need to monitor the behaviour of others if their behaviours are being overseen via surveillance, while there is every need to continually ensure that one's own indiscretions are not caught on camera. Although everyone is treated as a suspect under the CCTV camera's non-selective purview, those individuals who intentionally infringe established social rules already know that they do so. In contrast, one cannot necessarily identify if anyone else is covertly misbehaving, especially if one is encouraged to favour self-examination. Since everyone is treated as a suspect and each individual is cognisant of their own guilt-status, one may presume that other members of the populace are the "real" infringers who should be watched. Third then, continual monitoring fosters wariness of others. Fourth, because one cannot know who is lurking behind the surveillance lens, their motives are also likely to garner mistrust. The cumulative result is that one can only know oneself, and so no-one else can be fully trusted.

A further cause for anxiety stems from the as yet uncertain repercussions of such supervision; as Werth postulates, "how individuals ... respond to the State's efforts to regulate their conduct and govern their personhood remains under-theorized." ${ }^{20}$ Where theorisation has been advanced, it adds to fear culture's overarching unease. Several scholars have suggested that continual monitoring is likely to erode fundamental values, including privacy, dignity, and liberty. ${ }^{21}$ These concerns are articulated in torture porn's scripts. For instance, in Senseless, Eliott's request for "privacy" is refuted by Blackbeard's declaration that they "are broadcasting [Eliott] to the world." For Hunger's Jordan, the other hostages lose their dignity when they engage in "savage" acts of cannibalism. Attacks on the protagonists' liberty are foregrounded by the subgenre's characteristic focus on imprisonment.

Even more disconcerting is the possibility that panoptical surveillance might erode autonomy. As Epright posits, autonomy is inextricable from the ability to govern one's values and having to take responsibility for one's choices. ${ }^{22}$ Comprehensive surveillance implies that the individuals surveyed (that is, all individuals) are incapable of governing their decisions. Subsequently, governance is taken out of the individual's hands. Torture porn demonstrates why such power-shifts matter by depicting monitored individuals engaging in torture and even murder. Since those individuals are torn between self-preservation instinct, their moral principles, and the coercive power-structure to which they submit, the 
Linnie Blake and Xavier Aldana Reyes (eds.) Digital Horror: Haunted Technologies, Network Panic and the Found Footage Phenomenon. London: I.B. Tauris, 2016, pp.29-41

This version (C) Steve jones, 2015

captives are neither fully oppressed nor fully autonomous. By muddying autonomy in this way, these films underline that it is not clear whether abductees are responsible for any cruelty they enact.

Thus, rather than valorising brutality, torture porn offers a warning about the potentially damaging repercussions of "fear culture." As I have proposed above, torture porn's narratological focus is squarely centred on individual abductees; their torturers are relatively anonymous in comparison. In this regard, the film-perspective is typically aligned with the captor's point-of-view, but only insofar as the captives are continually monitored. This is not to suggest that the captives are objectified. Indeed, this perspective underlines the hostages' fear as they are subjected to the whims of a seemingly omnipotent, unidentifiable jailor. This perceived power-bias is reified by the panoptical apparatus that renders the protagonists visible and vulnerable. However, danger frequently stems from within the community of prisoners rather than from without. This arrangement is ubiquitous in torture porn films, which fast became one of the prevailing forms of horror fiction in the 2000s. There are clear reasons why this particular set of tropes became so popular during this period. These films resonate with the kinds of fear that contemporary digital surveillance instils. The latter is encapsulated in, for example, the outrage that followed the discovery in 2013 that the US National Security Agency has been engaged in mass surveillance on a global scale, accessing communication data via its PRISM programme. ${ }^{23}$ The programme epitomises panoptical power-bias inasmuch as those collecting data and the purposes of data gathering are inaccessible to anyone who is subject to surveillance: while the PRISM programme was classified "top-secret" (ultra-private), individual privacy is infringed by its operation. This incident characterises a broader uncertainty caused by digital surveillance, and the extent to which individual liberty and security might be threatened by surveillance techniques. Such anxieties are themselves part of a broader milieu of uncertainty that is collectivised under the banner "fear culture".

As thinkers such as Furedi and Gardner have proposed, widespread fear can erode one's ability to rationally assess the consequences of one's actions. ${ }^{24}$ Ergo, by skewing one's ability to gauge risk, fear culture may increase the populace's propensity for engaging in risk-activities. In torture porn, such activities include unthinkable acts of violence. This literal aggression has a further symbolic function. Bloodshed signifies the damage done to communal ties, which are ripped apart by self-motivated violence and the ruination of concepts such as autonomy, liberty, and equality, each of which are pre-requisites for functional intersubjectivity.

This is not simply to say that torture porn promotes communal decline by depicting it. In these films, infringements on autonomy, liberty, and equality are sources of horror. Torture porn's exaggerated representations of insecurity imply that stability is rooted in two elements that are lost in the panoptical system. First, the conditions allowing individuals to make free choices and take full responsibility for their actions must be defended, because autonomy is dependent on such circumstances. Second, individuals should reflect on their position relative to the powered-structures that situate them. Greater awareness regarding both one's dependency on the surrounding community and the limits of one's ability to selfgovern are crucial in developing intersubjectivity. In short, being aware of what is at stake in 
Linnie Blake and Xavier Aldana Reyes (eds.) Digital Horror: Haunted Technologies, Network Panic and the Found Footage Phenomenon. London: I.B. Tauris, 2016, pp.29-41

This version (C) Steve jones, 2015

relinquishing to reactionary impulses is form of self-defence (in both senses), since it means upholding the conditions that undergird autonomy.

Given that the bedrock of stable sociality is interdependent communality rooted in a robust conception of self-ownership, torture porn's panoptical cameras do not just capture individuals fighting for survival; they also capture struggles for the survival of individuality. This is not to say that torture porn roots for solipsistic nominalism. As Killmister notes, nominalists present "group membership [as] a handicap we should...shed" in favour of "pure" (autonomous) selfhood. ${ }^{25}$ Missing from this formulation is the recognition that autonomous selfhood is not possible without intersubjectivity, because we are social beings. Under pressure, torture porn's protagonists typically undertake a nominalist attitude, yet their actions are the product of reactionary paranoia and result in destructive violence.

In conclusion, by accentuating the impact such power might have on autonomy, torture porn offers warnings about where contemporary fear culture and surveillance cultures could lead. In these films, imperilled prisoners are focal-points for diegetic CCTV cameras and extra-diegetic film cameras alike. However, that does not mean torture porn contributes to communal decline by inviting "the audience to take a voyeuristic, sadistic and quasi-sexual delight in violence and mutilation," ${ }^{26}$ or encouraging audiences to engage in behaviours that contribute to "the coarsening of society," ${ }^{27}$ as critics have variously proposed. By concentrating attention on individuals in peril, torture porn spotlights that power originates at the micro-level, thereby contesting the vast, indeterminate nature of force in "fear culture." Since panoptical supremacy requires internalisation, the powerstructure begins with (and within) each detainee. Torture porn underlines that internalisation necessitates self-subjugation. Ultimately, the subgenre warns that individual complicity and weakness are more terrifying than outright oppression, since the latter is facilitated by the former.

\section{Notes}

${ }^{1}$ For a full dissection of torture porn and related issues, see Steve Jones, Torture Porn: Popular Horror after Saw (London: Palgrave-Macmillan, 2013).

2 See Kevin D. Haggerty, "Tearing Down the Walls: On Demolishing the Panopticon," in Theorizing Surveillance: The Panopticon and Beyond, ed. David Lyon (New York: Routledge, 2011).

3 For example, see Stephen Graham and David Wood, "Digitizing Surveillance: Categorization, Space, Inequality," Critical Social Policy 23, no. 2 (2003); Jan Kietzmann and lan Angell, "Panopticon Revisited," Communications of the ACM 53, no. 6 (2010).

\footnotetext{
${ }^{4}$ Michel Foucault, Discipline and Punish: The Birth of the Prison, trans. Alan Sheridan (New York: Vintage, 1995).

${ }^{5}$ Kelly (Alethea Kutscher) in Are You Scared?
} 
${ }^{6}$ Foucault, Discipline and Punish, 201.

${ }^{7}$ Ibid. 195.

8 Paul Jackson, Hosein Gharavi, and Jane Klobas, "Technologies of the Self: Virtual Work and the Inner Panopticon," Information Technology \& People 19, no. 3 (2006), 221-222.

${ }^{9}$ Foucault, Discipline and Punish, 201.

10 Ibid. 200. See also Michel Foucault, "The Eye of Power," in Power/Knowledge: Selected Interviews and Other Writings 1972-1977, ed. Colin Gordon, (New York: Pantheon Books, 1980), 152-157. Here, Foucault makes the distinction that Bentham "thinks of a visibility organised entirely around a dominating, overseeing gaze." Foucault shares the view that the gaze replaces the need for physical violence, but conceives of the panoptical system as "a machine in which everyone [observer and observed] is caught."

11 John to Jeff (Angus Macfadyen) in Saw III (Darren Lynn Bousman, 2006).

12 This is a recurring trope in the Saw series, for example (on this trait, see Steve Jones, "Twisted Pictures: Morality, Nihilism and Symbolic Suicide," in To See the Saw Movies: Essays on Torture Porn and Post-9/11 Horror, ed. John Wallis and James Aston (Jefferson: McFarland, 2013).

13 Michael Lusztig, "Charter Creep: Creeping Precommitment and the Threat to Liberal Republicanism," Canadian Journal of Political Science 43, no. 3 (2010), 689-90.

${ }^{14}$ Kelly Oliver, "Bodies against the Law: Abu Ghraib and the War on Terror," Continental Philosophy Review 42, no. 1 (2009), 68.

${ }^{15}$ Greg Elmer and Andy Opel, "Pre-Empting Panoptic Surveillance: Surviving the Inevitable War on Terror," in Theorizing Surveillance: The Panopticon and Beyond, ed. David Lyon (New York: Routledge, 2011), 145-149.

${ }^{16}$ Luke in Hunger.

${ }^{17}$ Ali Riza Taskale, "Clash of Nihilisms," in Domination of Fear, ed. Mikko Canini (New York: Rodopi, 2010), 84.

${ }^{18}$ Mikko Canini, "Introduction," in Domination of Fear, ed. Mikko Canini (New York: Rodopi, 2010), x; Frank Furedi, Culture of Fear Revisited (London: Continuum, 2007).

${ }^{19}$ Richard Fox, "Someone to Watch over Us? Back to the Panopticon," Criminal Justice 1, no. 3 (2001), 261.

${ }^{20}$ Robert Werth, "I Do What I'm Told, Sort Of: Reformed Subjects, Unruly Citizens, and Parole," Theoretical Criminology 16, no. 3 (2012), 329.

21 Ibid. 330; Fox, "Someone to Watch over Us?, 260; Suzy Killmister, "Why Group Membership Matters: A Critical Typology," Ethnicities 12, no. 3 (2012), 258; Josiah Ober, “Democracy's Dignity," American Political Science Review 106, no. 4 (2012), 827.

${ }^{22}$ M. Carmela Epright, "Coercing Future Freedom: Consent and Capacities for Autonomous Choice," Journal of Law, Medicine \& Ethics 38, no. 4 (2010), 801. 
${ }^{23}$ For information on the incident, see Christopher Kuner et al, "PRISM and Privacy: Will this Change Everything?" International Data Privacy Law 3, no. 4 (2013), 217-219; The Guardian's "NSA Files" sub-site http://www.theguardian.com/world/the-nsa-files, and the NSA's statement to the press about its activities, published on $31^{\text {st }}$ October 2013, http://www.nsa.gov/public_info/press_room/2013/NSA_Activities_Valid_FI_Targets.pdf.

${ }^{24}$ Furedi, Culture of Fear Revisited, xviii; Dan Gardner, The Science of Fear (London: Dutton, 2008).

${ }^{25}$ Killmister, “Why Group Membership Matters”, 255

${ }^{26}$ Chris Tookey, "The Man Who Made This Horrible, Misogynistic Film Needs to See a Shrink," Daily Mail (London), July 242009.

${ }^{27}$ Amanda Platell, "A Punch in the Face of Decency" Daily Mail (London), July 172008. 